\title{
The Digital Twin of the City of Zurich for Urban Planning
}

\author{
Gerhard Schrotter $^{1} \cdot$ Christian Hürzeler $^{1}$
}

Received: 8 November 2019 / Accepted: 16 January 2020 / Published online: 4 February 2020

(c) The Author(s) 2020

\begin{abstract}
Population growth will confront the City of Zurich with a variety of challenges in the coming years, as the increase in the number of inhabitants and jobs will lead to densification and competing land uses. The tasks for the city administration have become more complex, whereas tools and methods are often based on traditional, static approaches while involving a limited number of citizens and stakeholders in relevant decisions. The digital transformation of more and more pieces of the planning and decision-making process will make both increasingly more illustrative, easier to understand and more comprehensible. An important data basis for these processes is the digital twin of the City of Zurich. 3D spatial data and their models transform themes of the city, such as buildings, bridges, vegetation, etc., to the digital world, are being updated when required, and create advantages in digital space. These benefits need to be highlighted and published. An important step in public awareness is the release of 3D spatial data under Open Government Data. This allows the development of applications, the promotion of understanding, and the simplification of the creation of different collaborative platforms. By visualization and analysis of digital prototypes and the demonstration of interactions with the built environment, scenarios can be digitally developed and discussed in decision-making bodies. Questions about the urban climate can be simulated with the help of the digital twin and results can be linked to the existing 3D spatial data. Thus, the 3D spatial data set, the models and their descriptions through metadata become the reference and must be updated according to the requirements. Depending on requirements and questions, further 3D spatial data must be added. The description of the 3D spatial data and their models or the lifecycle management of the digital twin must be carried out with great care. Only in this way, decision processes can be supported in a comprehensible way.
\end{abstract}

Keywords Digital twin $\cdot$ Digital transformation in urban planning $\cdot$ Densification $\cdot$ Urban climate $\cdot$ Architectural competition · Participation

\section{Zusammenfassung}

Das Bevölkerungswachstum stellt die Stadt Zürich in den kommenden Jahren vor vielfältige Herausforderungen, denn die Zunahme von Einwohnerinnen und Einwohnern sowie von Arbeitsplätzen führt unter anderem zu einer Verdichtung und konkurrierenden Nutzungen. Die Aufgaben für die Stadtverwaltung sind komplexer geworden, wohingegen die Werkzeuge und Methoden oft auf traditionellen, statischen Ansätzen beruhen und eine begrenzte Anzahl von Bürgern und Interessengruppen in relevante Entscheidungen einbeziehen. Durch Digitalisierung von Schritten in der Planung wird der planerische Prozess inklusive der Entscheidungsfindung ins Digitale transformiert und damit immer anschaulicher, verständlicher und nachvollziehbarer. Eine wichtige Datengrundlage für diese Prozesse ist der Digitale Zwilling der Stadt Zürich. Er bildet durch 3D Geodaten und deren Modelle Themen der Stadt, wie Gebäude, Brücken, Vegetation, usw., räumlich in der digitalen Welt ab, wird je nach Bedarf mit unterschiedlicher Frequenz nachgeführt und schafft Vorteile im digitalen Raum. Diese Vorteile müssen aufgezeigt und bekannt gemacht werden. Ein wichtiger Schritt dazu ist die Veröffentlichung von 3D Geodaten unter Open Government Data. Damit können Anwendungen kreiert werden und das Verständnis gefördert bzw. der Aufbau von unterschiedlichen Kollaborationsplattformen wird vereinfacht. Mit der Visualisierung und Analyse von Digitalen Prototypen und Aufzeigen von Wechselwirkungen mit dem bebauten Umfeld können Szenarien digital entwickelt und in

Gerhard Schrotter

gerhard.schrotter@zuerich.ch

1 Public Administration, City of Zurich, Zurich, Switzerland 
Entscheidungsgremien diskutiert werden. Fragestellungen zum Thema Stadtklima können mithilfe des Digitalen Zwillings simuliert werden und Ergebnisse wiederum an die bestehenden 3D Geodaten angeknüpft werden. Damit wird der 3D Geodatensatz, die Modelle und deren Beschreibungen in Form von Metadaten zur Referenz und diese müssen, den Anforderungen entsprechend, nachgeführt werden. Je nach Bedarf und Fragestellung müssen weitere 3D Geodaten hinzugefügt werden. Die Beschreibung der 3D Geodaten und derer Modelle bzw. das Lifecycle-Management des Digitalen Zwillings müssen mit hoher Sorgfalt vorgenommen werden. Nur so können Entscheidungsprozesse nachvollziehbar unterstützt werden.

Schlüsselwörter Digitaler Zwilling · Digitale Transformation in der Stadtplanung · Verdichtung · Stadtklima .

Architekturwettbewerb · Partizipation

\section{Environment and Strategies}

The Canton of Zurich expects an increase of the population by 280,000 people by the year 2040 . According to the canton's guidelines, $80 \%$ of this growth shall take place in urban regions to conserve the scarce resource of land. According to those scenarios, around 520,000 people could live within the city limits of Zurich in 2040, and the number of jobs will increase accordingly. This growth will confront the City of Zurich with many challenges in the coming years, as the increase in the number of inhabitants and jobs will have positive and negative effects. The city benefits from the increase in importance and diversity, from more economic and cultural innovations. At the same time, the competition of land uses will increase more and more. The densification of the existing residential areas under consideration of quality standards is, therefore, the main task. The grown identity and individuality of the urban quarters should be preserved. In addition, noise and usage conflicts must be minimized. In the context of sustainable growth, the challenges and strategic objectives have been described and set out in the Strategies Zurich 2035 (2015).

With the strategy focus Digital City (2019), the city council strengthens and accelerates the digital transformation in the city administration. The focus Digital City supports the strategy Smart City Zurich (2018). It uses the opportunities of digitisation to the benefit of the population, the companies and the city administration. For the City of Zurich, smart means networking people, organisations and infrastructures in such a way that social, ecological, and economic benefit will be created. The networking of data, sensors and applications allows new and more efficient solutions for the users of urban infrastructures as well as for their operators. The good networking strengthens participation opportunities for the citizens and their contact with the administration. Numerous projects in various areas have already been implemented or are being planned. Smart City Zurich provides a common framework for these ongoing activities and planned measures.
One of the six sub-programmes of the Digital City (Fig. 1), an important lighthouse project of the Smart City Zurich, is the so-called digital twin of the City of Zurich: the digital, spatial image. The City of Zurich, like Helsinki (2019), Munich (München 2018) and Rotterdam (2019), has opted for this terminology. Other cities such as Singapore are striving for a digitalization of reality and platforms for accessing and designing applications with the name Virtual Singapore (2018). The term digital twin creates a proximity to the construction and real estate industry and thus builds a bridge to the new developments in the field of Building Information Modelling (BIM; BauenDigital 2019) and digital transformation in the construction industry. Although the term is used there for a single building only, the mental bow can be made to further infrastructure and to the urban space itself. The ultimate goal is a digital representation of the city to simulate issues such as urban planning in climate change. For this purpose, components of the digital twin must be updated with different intervals and, where appropriate, enriched with real-time data. In the triangle of the real (physical), social and digital world, the digital twin connects the real world with the digital world or, more precisely, its space. Thus, in addition to the "traditional" link between social and physical space and the link between social and

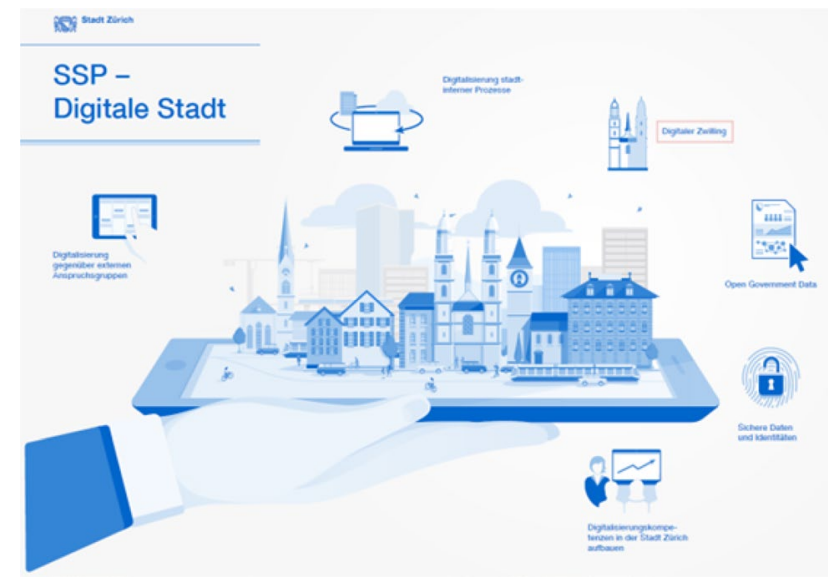

Fig. 1 Strategic focus Digital City with the six sub-programmes (source: City of Zurich) 
digital space—supported by e.g. social media — this new link is emerging (Rotterdam 2019). The digital twin opens up new perspectives for urban planning. The new applications bring more understanding, more targeted questions and thus comprehensible answers to future-relevant topics.

\section{History: The 3D City Model}

The first experiments with spatial data were carried out with ETH Zurich as early as the 1990s. The definitive, so-called 3D city model was created in 2011. ETH Zurich, Fachhochschule Nordwestschweiz and TU Munich were involved in the development. Various agencies of the public administration have bundled their forces. The GIS Competence Centre of the Department of Building and Planning and the GIS Centre for Geomatics + Surveying have launched the first draft. The digital terrain model (LoD0), the block model (LoD1), and the roof model (LoD2) are available in the reference system $\mathrm{CH} 1903+$ (reference frame LV95/EPSG 2056).

The terrain model is based on the grid file of the Canton of Zurich, generated from LIDAR images from 2014 with a resolution of $50 \mathrm{~cm}$. In bridge areas, additional break lines were recorded. Manual adjustments were made in areas of Lake Zurich and the Limmat. The road geometries of the official cadastral survey were additionally introduced as break lines. The irregular triangular mesh was calculated by FME with the tolerances of $1 \mathrm{~m}$ and $0.1 \mathrm{~m}$. The mean height error is $30-40 \mathrm{~cm}$. The basic data set dates back to 2014 .

The block model is based on the real and planned building floor plans of the official cadastral survey, the height of which is below the terrain. The heights of eaves and gables determined by photogrammetry are assigned as attributes to the floor plans. In buildings with a high recognition factor and striking differences in height, the floor plans are subdivided so that the buildings are represented by several prisms of different heights. In addition to the buildings, the 3D block model contains striking bridges. The mean position error is within the limits of the official cadastral survey and amounts to $10-15 \mathrm{~cm}$ and the mean height error amounts to $50 \mathrm{~cm}$. The data set is continuously updated.

The roof model consists of the walls and detailed roof structures of the buildings. Analogous to the block model, the building floor plans serve as the basis for the official cadastral survey. The evaluation of the roofscape takes place by means of semi-automatic stereo aerial photogrammetric evaluation. In addition to the buildings, the model contains striking bridges and walls.
Thus, the digital terrain model, over 50,000 buildings in various levels of detail as well as walls and bridges are available. The 3D spatial data are mainly used in the city administration in the fields of environmental and urban planning or submitted as a subset to third parties for visualization of planned construction projects. The requirements for content, accuracy, tracking and reliability have been developed in collaboration with various service departments of the City of Zurich. This collection of 3D spatial data is summarized under the term 3D city model (Stadtmodell 2019) (Fig. 2).

\section{Digital Twin for the City of Zurich}

The digital twin is a spatial, digital model of the City of Zurich for different themes. It extends the existing spatial data infrastructure with 3D spatial data and their models and describes it. The focus is on 3D spatial data and it becomes the reference to consequently link spatial and other data. The processes, the data acquisition and update, are fully described for the 3D spatial data, the models and the metadata. As a consequence, the processes in cadastral and engineering surveying must also be adapted, meaning that the third dimension must be taken into account when digitizing space and performing further processing.

Spatial data, spatial data models, and spatial metadata are defined by the Federal Act on Geoinformation (GeoIG 2007), and have been described in detail. The Act is fully "Infrastructure for Spatial Information in the European Community" (INSPIRE) compliant and even goes beyond the INSPIRE Directive, although it is not an actual transposition of the Directive, since Switzerland is not an EU Member State. Compared to other European countries there was a formal Spatial Data Infrastructure in place in Switzerland before the implementation of INSPIRE (Crompvoets et al. 2018) and based upon the Federal Act on Geoinformation a solid governance framework has been developed.

The Act on Geoinformation describes 3D spatial data as the extension and characteristics of certain spaces and

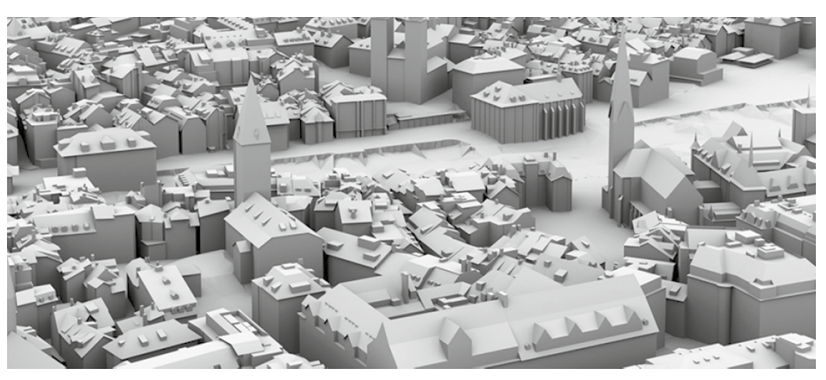

Fig. 2 3D city model with terrain, block and roof model (source: City of Zurich) 
objects, in particular their location, condition, use and legal relationships, with a certain reference to time. The spatial data models are representations of reality, which determine structure and content independent of a specific spatial data system. The formal descriptions of the characteristics of spatial data are based on metadata, such as origin, content, structure, validity, timeliness, accuracy, usage rights, access options or processing methods. Metadata are an essential component for establishing and operating a geodata infrastructure. Without metadata no valid decisions and actions can be derived from geodata. Even a proper search for specific geodata cannot be done without proper metadata. Geocat (GeoCat 2019) is the metadata catalogue for Swiss spatial data. Federal offices, cantons, municipalities and private companies record the data.

The concept of the digital twin according to Grieves (2014) originates from the product lifecycle management. If this concept is applied to spatial data, models and metadata, then these can be described on the basis of a product life cycle. The product life cycle describes the sum of the individual phases through which a product passes along the time dimension. Therefore, in addition to the detailed description of the spatial data and the spatial data models (via metadata), their life cycle is also described. Thus, the development of different components of the digital twin (buildings, roads, etc.) can be digitally planned and updated, and can be renewed or maintained on the basis of a defined interval.

Updates may happen in short intervals and this may, but does not have to, be related to the so-called High-Frequency and Low-Frequency City (Batty 2018; Wildfire 2018). Even in a Low-Frequency City, elements which in reality undergo rapid changes and contain time-critical information (e.g. by means of real-time sensors) are to be linked to the digital world.

Vivid examples can be observed in the construction and real estate sectors (DigitalTwinCMU 2019). There, construction processes and then maintenance are digitally mapped using 3D spatial data and a building model as a digital replica that shows the structure and behaviour of a building with interactive connections to the physical object. The interactive connections transmit information such as status, usage or analysis data as well as control commands. Depending on the level of detail and automation as well as the type of connections and information, this component of the digital twin can reach different characteristics. It thus depicts the structural and operational conditions of a real building over time. It can depict an existing building or one under construction.

It is irrelevant whether the counterpart already exists in the real world, will exist in the future (Wikipedia 2019), or perhaps will not be realized at all. The digital prototype is built before reality and thus enables predictive modelling.
The predictive modelling and the reactive modelling, immediate action in both digital and real space, are described in Wildfire (2018). In predictive modelling, a distinction is made between iterative feedback and sandbox testing. This means that the most diverse simulations and scenarios in the digital world can be enriched, created and analysed with empirical values from reality. This is described in Grieves (2014) under the term of digital prototypes and the environment of the digital twin.

For the City of Zurich, the digital twin means a consistent enrichment of the 3D spatial data inventory and, in addition to the modelling and description of the data, a lifecycle management of the individual components as well as the entire data inventory. The 3D spatial data are the basis for linking further spatial data or other data. Where appropriate, elements from reality are linked to the digital world in real time. The processes for digitizing reality are extended by the third dimension.

The developments are managed by the GIS City of Zurich (GIS Stadt Zürich) and implemented together with the partners ( 25 service departments of the City of Zurich). Almost 20 years ago, the need for coordination in the field of spatial information in the city was recognised. As a result, comprehensive spatial information projects were jointly implemented, thus laying the foundation for the urban spatial data infrastructure (SDI). In 2009, the City Council approved the comprehensive strategy for GIS City of Zurich (GIS Stadt Zürich). In 2019, the strategy was revised again or adapted to the new challenges (GISStrategie 2019).

With the expansion of the geodata infrastructure and the technical platform, the digital twin can be used for locationbased cooperation with internal and external partners. For example, planned real estate projects or urban development scenarios can be integrated. The data also offer optimal conditions for presentation, discussion and the shaping of the public space. The basis for various analyses and calculations such as visibility, noise propagation and solar potential analyses, shadow calculations, flood simulations, etc. is created.

\section{Planned, Selected Extensions}

Due to new requirements of the service departments of the City of Zurich, coordinated by the GIS City of Zurich (GIS Stadt Zürich), projects are carried out which extend the database. These data are then made available again and enable new applications.

\subsection{Street Space 3D}

To capture data efficiently or simply to reduce the need for inspections, the public space of the City of Zurich is 
captured in three dimensions, integrated into the digital twin and made available via an Intranet solution. In autumn 2020, Geomatics + Surveying will make an imaging service available to all municipal employees, in which the street space can be re-experienced digitally. In addition, it will be possible to capture further objects in $3 \mathrm{D}$, to measure objects and to visualize existing data.

\subsection{Utility Cadastre 3D}

Since July 2013, 2D pipelines and cable data (utility cadastre) of the City of Zurich have been submitted by the utility owners to Geomatics + Surveying. The utility owners are the Electricity Service, Energy $360^{\circ}$ AG, Disposal and Recycling Services, Water Supply Service, Public Transport Service and telecommunication companies. Most of the utilities have been digitized from continuously updated plans. The position accuracy is in the range of $\pm 20 \mathrm{~cm}$. Pipelines and cables, e.g. due to construction work are marked as inaccurate. The utility cadastre of the City of Zurich is a subset of the digital documentation of the work management of the utility owners. At least once a week, the pipeline and cable owners automatically deliver the new data to the register operator (Geomatics + Surveying). The suppliers remain responsible for the content of the data (punctuality, completeness, position accuracy, etc.). The operator is responsible for ensuring that the uploaded data is complete, up-to-date (as agreed) and not modified.

The utility owners of the City of Zurich are already recording $3 \mathrm{D}$ coordinates today. However, this information is lost at the interface to the utility cadastre. This gap in the data flow will soon be closed to enable the delivery of BIMcapable utility cadastral datasets.

In the Digital Underground project (van Son et al. 2018) at the Singapore-ETH-Centre, in cooperation with the Singapore Land Authority and industrial partners, various measurement methods are being evaluated for already laid utilities where the location or depth is uncertain or no useful information is available. In addition to the measurement methods, new modelling approaches (Yan et al. 2019) are also being explored. Also, an exchange platform DUConnect has been created to share and discuss experiences worldwide.

\subsection{More Detailed Models}

The FCL Virtual Singapore project investigates methods to model 3D building data more realistically. The focus is on the efficient modelling of façades on the basis of existing roof models. Using different raw data from the latest technologies and methods (such as laser scanning, photogrammetry) and parametric modelling, geometrically correct façades can be generated and the accuracy or deviation of the models from reality can be determined. The process and the detailed contents of the research packages can be found under Gruen et al. (2019).

Other infrastructure elements such as bridges, highvoltage lines, etc. are added to the digital twin as required as additional components. In cooperation with the city and underwater archaeology, also historical 3D spatial data are constructed. Thus, the history of the city can be experienced interactively in different time periods. From the first pile dwellings through Roman Zurich and the Middle Ages to the present day. The demand is controlled by projects from service departments or based on strategic formulations from the GIS City of Zurich (Fig. 3).

\section{Enabler}

To make the digital twin known, it is necessary that the data sets are made available as Open Government Data. This results in initial visualizations and analyses as well as economically profitable applications. In addition, the large amounts of data must be visualized (Zürich virtuell) and have to be easily accessible through an advanced geoportal.

\subsection{D Building and Terrain Data are Open Government Data}

Simple access and the free use of administrative data, without the need for specific protection (Open Government Data; OGD for short), is part of the basic infrastructure of a digital city. OGD is further developed according to the "Open by Default" principle. Since 2012, the City of Zurich has been providing data from public administration free of charge, machine-readable and under a free licence. An OGD policy and guidelines have been issued, made binding city-wide and put into effect. The OGD Internet Portal contains the Open Data Catalogue as well as information on handling of open data, application examples and further information about Open Data. End of 2018, the terrain model, block model and roof model were also published on the OGD platform. This upshift was accompanied by a media conference.

From the media conference on 12 November 2018 until 20 September 2019, a total of 11,722 data sets were downloaded from the OGD portal (Fig. 4). The five data sets of the 3D spatial data (Fig. 4) already correspond to about onethird of all downloads in this period. This makes 3D spatial data the most frequently used data of this portal. Geodata in 
Fig. 3 Data levels and extensions of the digital twin: street space, trees, archaeological objects, underground, power lines, BIM model, bridges (source: City of Zurich)
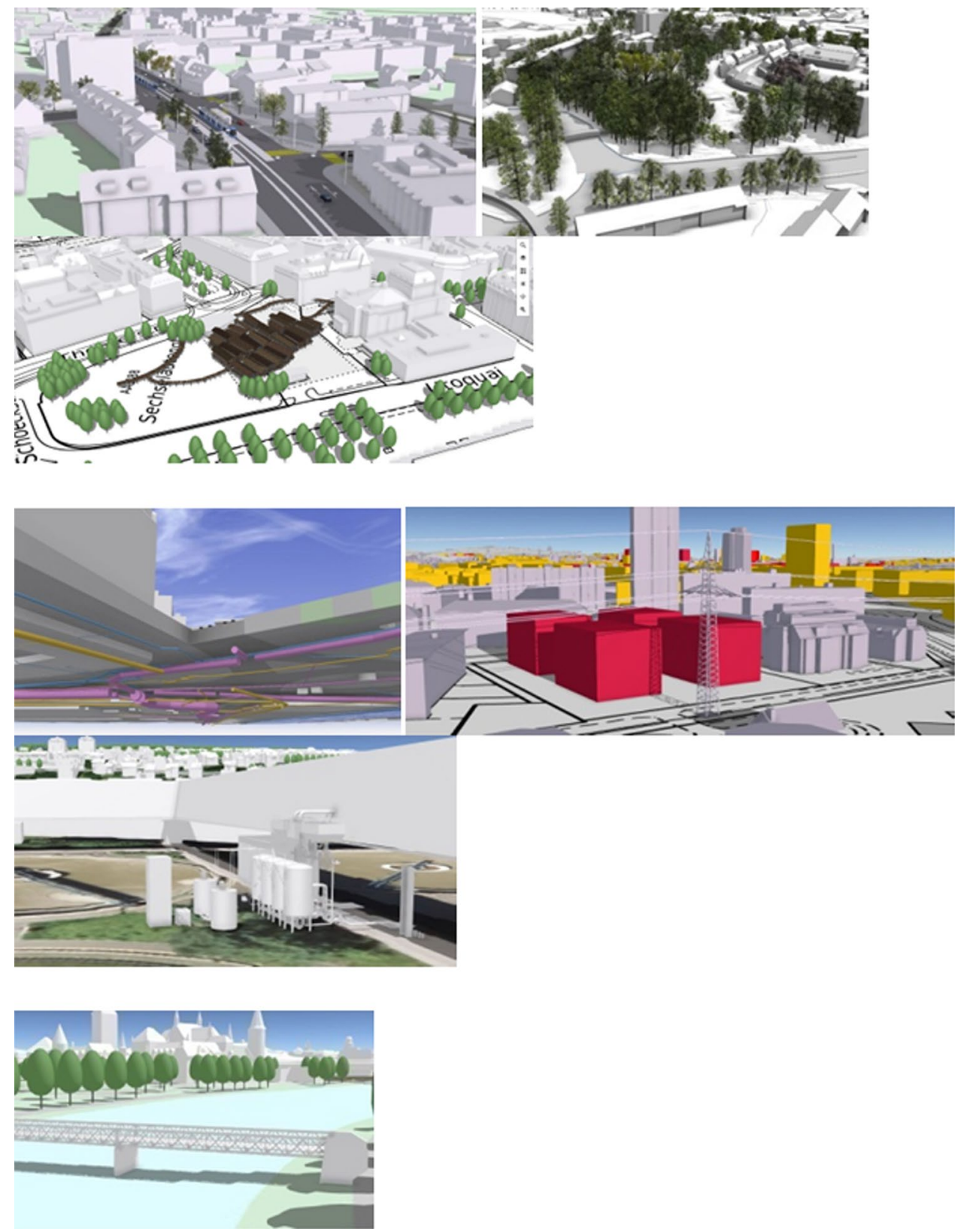

Fig. 4 The five most downloaded data sets on the OGD portal of the City of Zurich are 3D spatial data (source: City of Zurich) 
general were downloaded 7422 times. This corresponds to about $65 \%$ of the downloads.

The free access of administrative data simplifies the use enormously. This opens up new value creation opportunities for private individuals and the cooperation of project partners. In addition, reliable digital data is an indispensable basis for new business models, such as start-ups around the Internet of Things, Smart City solutions, location-based gaming worlds, etc.

\subsection{Open Government Data Application}

A first successful application of the component 3D building of the digital twin of the city was realized by the company Blindflug Studios with the game "(re)format Z:", a game about the Reformation in Zurich (Fig. 5). The history of the Reformation is embedded in a dystopian cyberpunk version of the city. In this way, people who would otherwise not be interested in the topic are to be addressed.

It has been decided to create the game in $3 \mathrm{D}$ as this is the best choice for an immersive experience. To be able to complete the project "(re)format Z:" within a short timeframe and to ensure that an accurate representation of the city is created, the 3D buildings of the City of Zurich have been used. The model contained the external shape of the houses including the roofs and the elevation data of the ground.

A high degree of detail was to be achieved. The building data have been used as a basis. The detailed version has been created directly on the model, with a newly developed system, which allows the multiple reuse of elements such as windows and doors. With the "toolbox" of about 100 individual components the centre of Zurich's old town, including the most prominent locations such as the Grossmünster, the old town hall and the Fraumünster has been erected.

After a development period of about 7 months, the team was able to release "(re)format Z:" in November 2017. Thanks to the interesting setting, 25,000 downloads have been made within 3 weeks and the first place on the "Top Free Puzzle Games" list in the App Store has been reached. At the beginning of 2019, 100,000 downloads and 24,500 h of total playing time were reached worldwide. At the end of 2019 , the game will still receive around 80,000 impressions per week in the App Store.

\subsection{Geoportal}

The Geoportal simplifies the collection and assembly of spatial data. The desired topics can be selected for certain areas and then automatically requested. Currently, more than 200 spatial data sets are available in raster and vector format.

The geoportal enables the systematic and automated viewing of all geodata on the Internet. Also, the automated update of data and metadata and the connection to the OGD portal are guaranteed. The customer can order not only urban but also canton's data via a "Single Point of Contact". The geoportal is online since the end of 2019 (GeoPortal 2019).

\subsection{Zürich Virtuell (Virtual Zurich)}

Virtual Zurich opens a window (viewer) on the digital twin. The viewer is intended to facilitate the visualization of 3D components. In the future, the 3D models can be viewed and used interactively in the Intra- and Internet via a web interface (Fig. 6). The requirements of the GIS City of Zurich are incorporated into the implementation. In addition to public access, there will also be exclusive rooms. These exclusive
Fig. 5 Excerpts from the game "re(format) Z:" and development tools (source: Blindflug Studios)
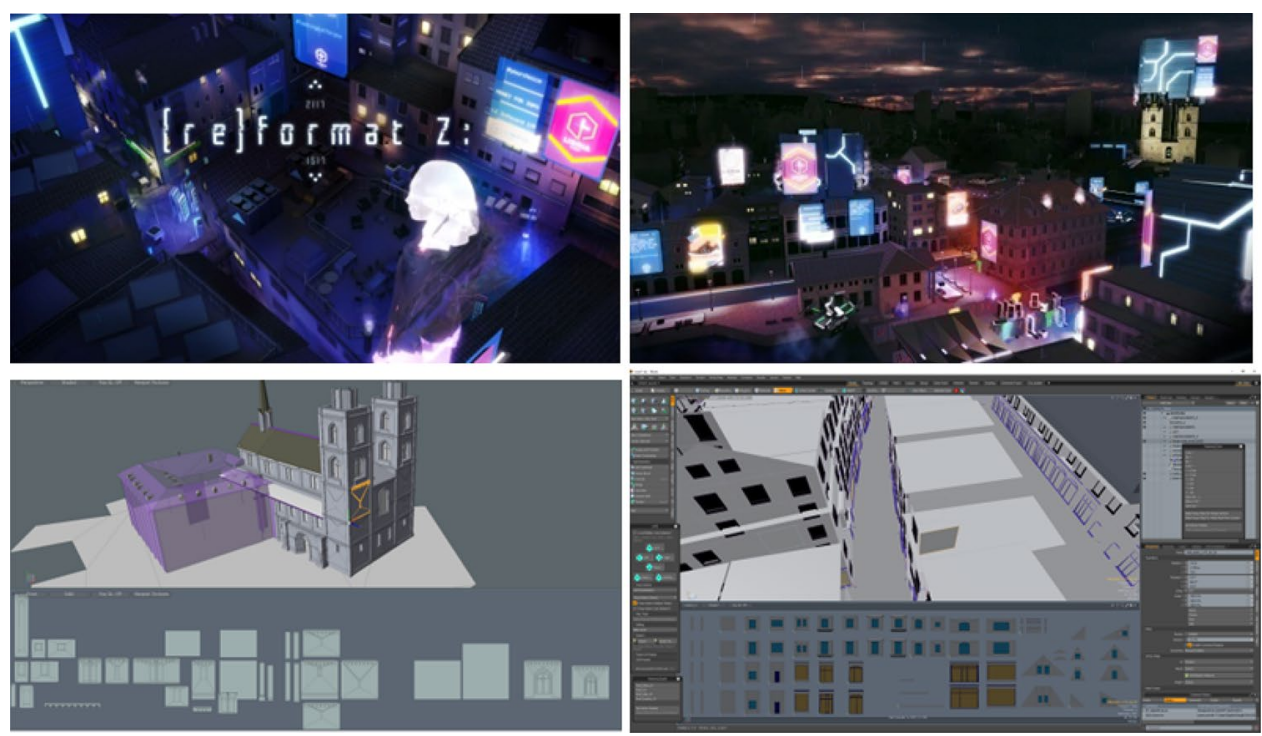

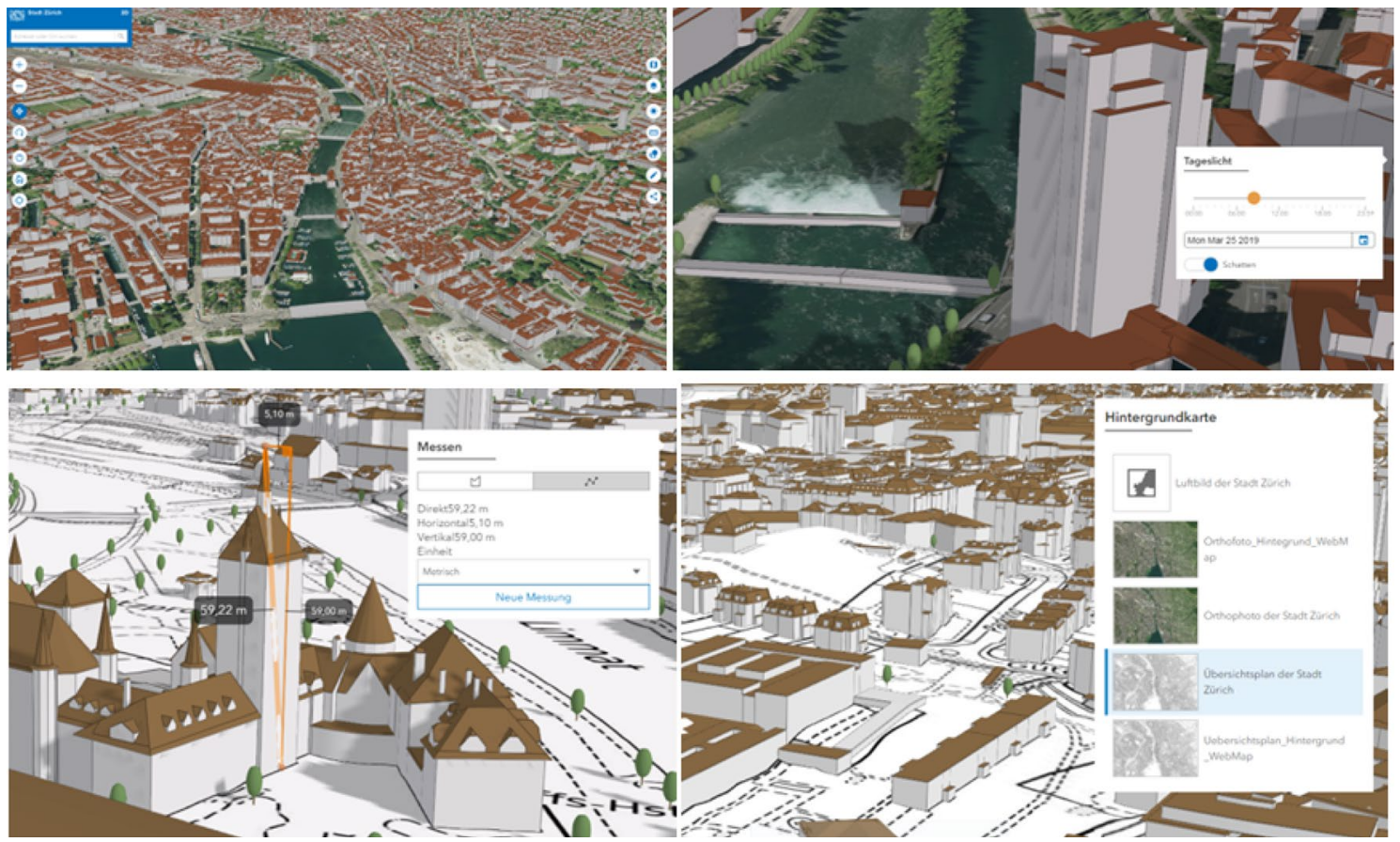

Fig. 6 Zürich virtuell: preview of the new window on the digital twin (source: City of Zurich)

rooms can be used, for example, to visualize construction projects and make them available to a selected group of people. At the moment the technical implementation is in progress and the viewer will go online in Q1 of 2020.

\section{Applications}

Over the last 10 years, 3D spatial data have become increasingly established as a solution for spatial tasks. Like many other cities, Zurich uses its virtual city model in the areas of environment (e.g. noise, air pollution and
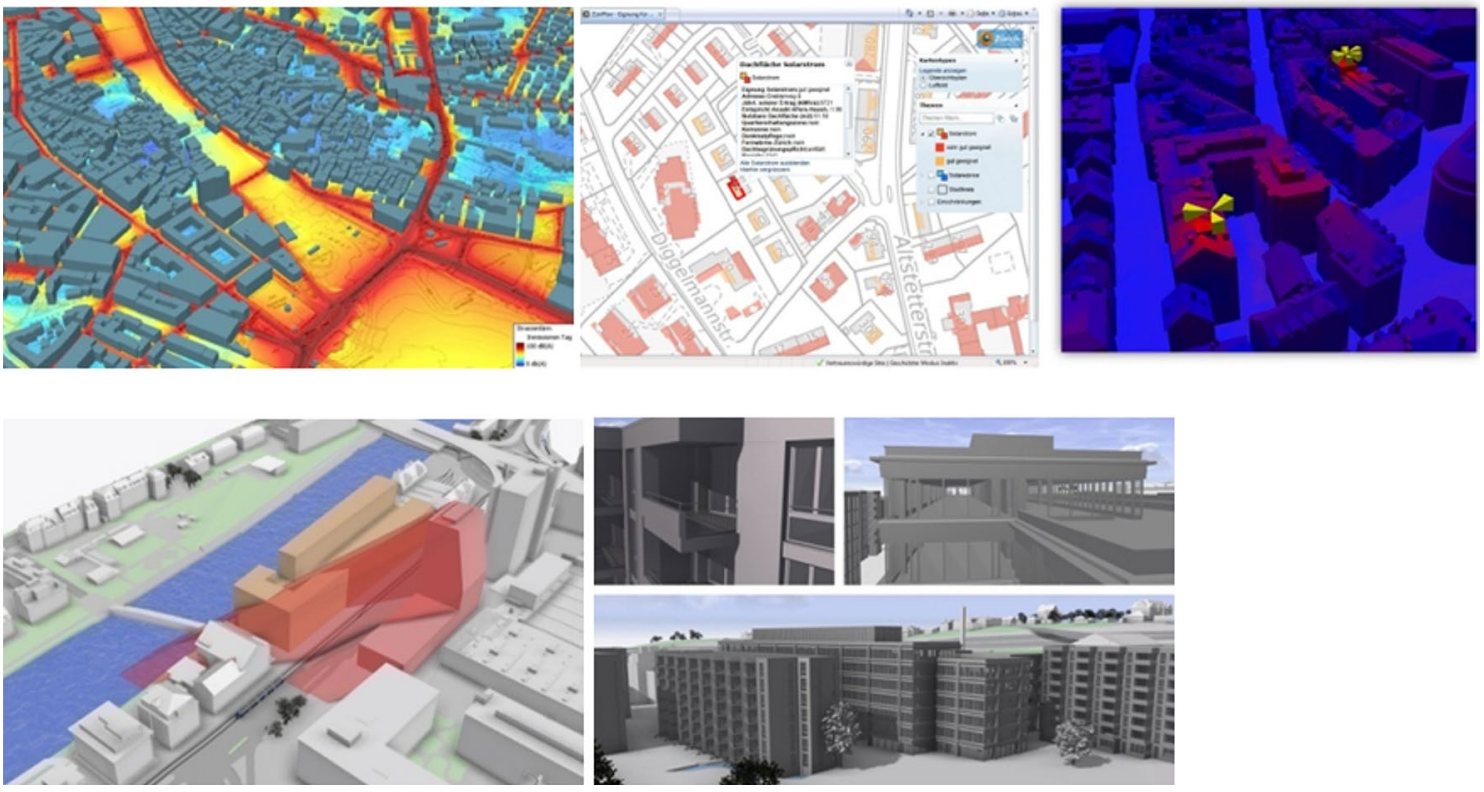

Fig. 7 Established applications: noise (upper left), air pollution (upper centre), mobile phone radiation (upper right), solar potential (lower left), visualization of construction projects (lower right) (source: City of Zurich) 
mobile phone radiation modelling), energy (e.g. solar potential analyses), urban planning (visualization of construction projects, shadow and visibility analyses) and in other areas (Fig. 7). These applications are now established and described in detail, e.g. in "Applications of 3D City Models: State of the Art Review" (Biljecki et al. 2015). In the following, therefore, novel, still little-used applications of digital twins are described using the example of the City of Zurich with a focus on urban planning.

\subsection{Municipal Development Plan (Kommunale Richtplanung)}

The City of Zurich is growing. According to predictions, by 2040 about 100,000 or $25 \%$ more people could live within the city limits. The demand for space not only for living and working space, but also for infrastructure as well as open spaces and green spaces is therefore increasing. With the first development of the "Municipal Structure Plan for Settlements, Landscape, Public Buildings and Facilities" (Richtplan 2018), which is binding on the authorities, the City of Zurich is demonstrating how the requirements

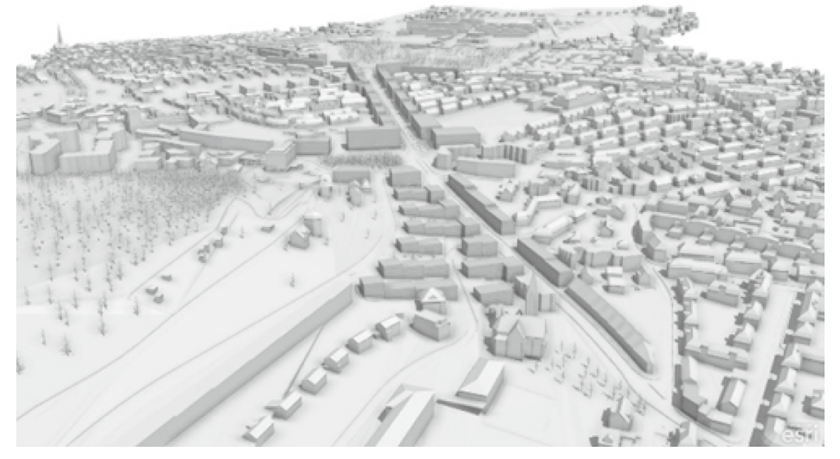

Fig. 8 Urbanization study (source: City of Zurich) for high-quality spatial development are being met. The planning horizon for the municipal development plan is 20-25 years.

Various basic principles such as guidelines and concepts were created for the development of the municipal structure plan. For the visualization of a desired spatial development in the first phase of the development of the municipal structure plan, various urban development studies were developed and presented in a digital three-dimensional model.

These 3D models of different parts of the City of Zurich essentially contained the following three data levels: the current building development (from the digital twin), the maximum building capacity according to the current zoning (from a parametric model of the Esri City Engine) and possible target images in the form of various compaction scenarios (from urban development drafts). The visualization of the 3D model in an interactive web application enabled the planners of the city administration to make a vivid comparison of these levels and served as a valuable basis for discussion (Fig. 8). Thanks to the linking of the geometric data with various planning parameters (e.g. building utilisation, floor space, number of inhabitants and workplaces), analyses could also be carried out and quantitative statements derived from the 3D models.

These data subsequently formed the basis for the development of the municipal development plan. To illustrate and deepen its contents, a WebViewer was also created in which the various contents of the municipal planning can be combined.

\subsection{High-Rise Planning}

Zurich is growing and developing. Because of the current growth predictions, the Office for Urban Development of the City of Zurich intends to update the valid high-rise guidelines and the high-rise areas defined in the building and
Fig. 9 Web-based 3D application of the high rises (source: City of Zurich)

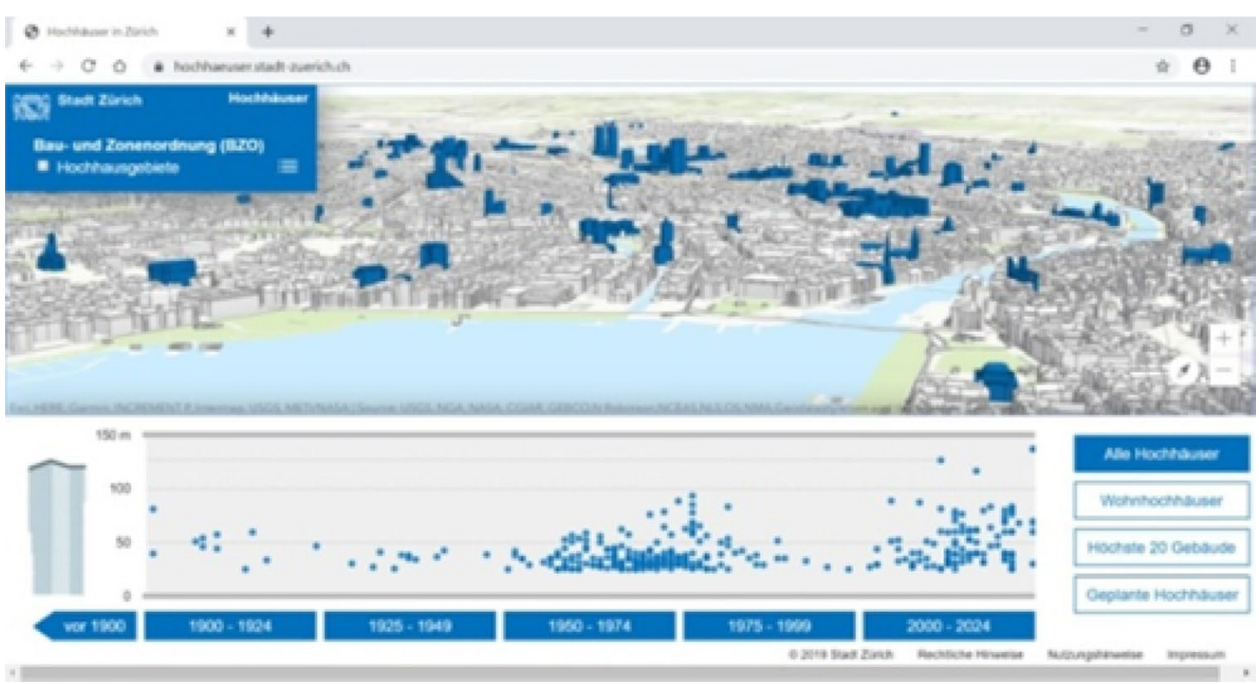


zoning regulations. In a two-stage procedure, interdisciplinary project teams are investigating the future development of high-rise buildings in the City of Zurich.

As part of this process, the Urban Planning Office created a 3D interactive application on the Internet (Fig. 9). It shows all existing and planned high rises of the city in a temporal-spatial model. The 3D map is based on an application from New York City, NY, U.S., whose program code is "Open Source" and could be adapted for Zurich with little effort. The most important data basis of the application is the digital twin. It provides the spatial representation of the high-rises in 3D. Thanks to intelligent linking with a building database, it was also possible to make the years of construction of all high-rise buildings available.

The application is freely available on the Internet at Hochhaus-Viewer (2018). For those involved in the project, further planning-relevant data can be activated via login and planning drafts can be visualized directly in the three-dimensional model and checked for urban development.

\subsection{Urban Climate}

Urban areas are considered particularly sensitive to the effects of climate change. Projects such as "Cooling Singapore" (2017) try to explore holistic planning solutions and develop various strategies. According to the "Climate Scenarios for Switzerland" (CH2018 2018), an average of 21 heat-days is expected for the City of Zurich in 2060; today it has an average of 6 heat-days. Those and tropical nights can lead to health problems, especially for sensitive groups such as the elderly, weakened people and children. Since the influence of the City of Zurich on global climate change is limited, adaptation measures for the urban climate must be implemented to counteract local overheating. Climate adaptation is therefore one of the most important new challenges for urban development.

Zurich is responding to the consequences of climate change with its considerations on climate adaptation and the "Sectoral Planning on Heat Reduction", which will be published in 2020. Measures to maintain and improve the cooling of the city are one of the focal points. Due to its location on the lake and its topography, Zurich has a well-functioning cold air system. The thermal load of the bottom of the valley of the city is reduced at night by the influx of cool air from the surrounding hills. In areas with distinctive cold air corridors, the orientation, extent and height differentiation of buildings are decisive for good ventilation of the city.

As part of the "Sectoral Planning Heat Reduction", the effects of planned buildings on the city's cold air flows were analysed for selected urban areas. The analysis was carried out with a GIS-based 3D model, which was built with various data of the digital twin (terrain, existing and planned buildings, tree locations, etc.). On the basis of meso- and

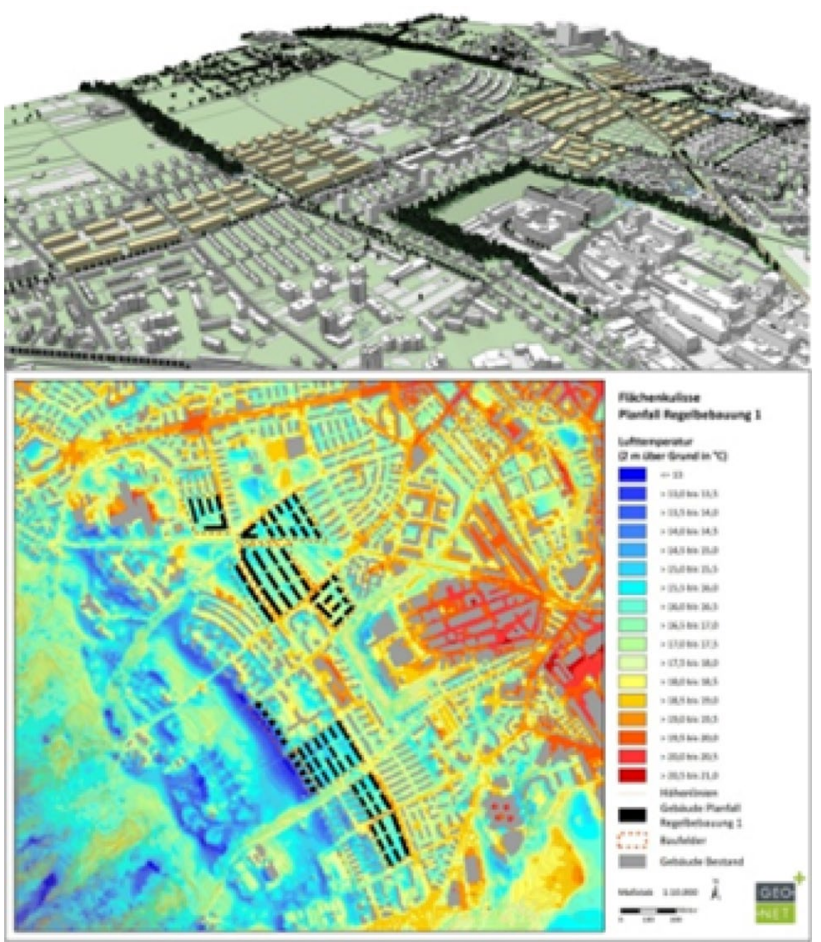

Fig. 10 Temperature analysis of a building study. (source: City of Zurich)

micro-scale climate models, the obstacle effect of planned buildings could be determined and compared with the current development. The analysis has shown that, depending on the spatial characteristics (length, width, height, position), new buildings have a provable influence on climateecologically relevant factors such as temperature (Fig. 10), wind and cold air volume flow.

Thanks to reliable data from the digital twin, climate issues can now be better integrated into the planning decision-making process. Together with other factors such as noise, traffic, urban planning, etc., the climate is establishing itself as an additional basis for decision-making in planning procedures. In Zurich, the results of GIS-supported climate studies will now be used, for example, for variant decisions on public-sector construction projects. In addition to the current development, the City of Zurich has therefore recently integrated construction planning into the digital twin, thus making it optimally usable for applications such as climate analyses.

\subsection{Architectural Competitions}

In architecture and urban planning, competitions are held to find the optimal design for an idea or a concrete planning task. In its long tradition, the architectural competition has contributed to a high and sustainable building culture. The City of Zurich has been supporting and cultivating 
this tradition for many years. The Office for Building Construction (Amt für Hochbauten) organises an average of ten competitions each year for new construction projects in the public sector and for non-profit property developers.

Architectural competitions have been held in analogue form for years. Although all participating architectural firms now draw their plans digitally on the computer, they must print them out and submit them together with a model. The jury's assessment of the entries will be based exclusively on the plans printed on paper and the physical models. With the ongoing digitization of administrative processes and the increasingly digital way of working in architectural offices, this completely analogue process flow is being questioned by many participants.

The Office for Building Construction is carrying out pilot projects to examine the implementation of competitive projects with the support of digital tools. The focus of this digitization effort is the phase of the judging process. Two new digital tools, based on the digital twin, will support the evaluation of the submitted designs. In the first tool, the participants will be provided with a web-based 3D map in which the 3D model of the competition entry will be checked and submitted later (Fig. 11). This 3D map with integrated contribution is projected onto a screen during the judging process. To form an opinion, the jury can jointly view the individual models, change perspectives, change scales, compare designs synchronously in perspective and, if necessary, display spatial data such as construction lines (Baulinien).

The second digital tool is an Augmented Reality (AR) application. With the help of the HoloLens AR glasses, the designs and their extensive surroundings are projected from the digital twin as an interactive 3D hologram into the judging room. Drafts can be compared, shadows simulated, spatial data switched on, scales changed and cross-sections generated. It will be examined whether this application can replace the use of physical models in the long term. The AR application also allows the visualization of the drafts on site on a scale of 1:1 (Fig. 12). This leads to a visual fusion

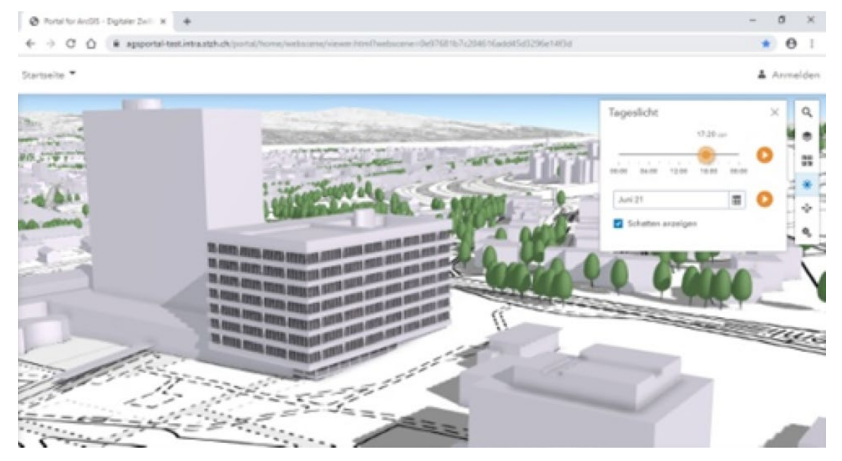

Fig. 11 Web-based 3D application with design from an architecture competition (source: City of Zurich)

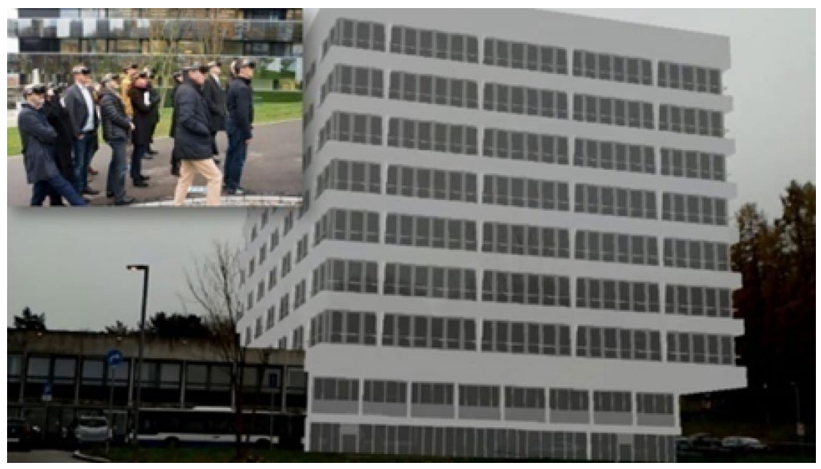

Fig. 12 Augmented reality application with design from an architecture competition (source: City of Zurich)

of digital design and real environment. The jury can thus compare the volumetric of the contributions in the context of their environment and let them work on themselves. The use of AR in architecture and other areas of application will further expand the use of the digital twin.

Digital support for further steps in the competition procedure will also be examined. This includes: the digital submission of all planning-bases in 3D from the digital twin to the participants, the submission of the digital models as a simple BIM model, the computer-aided preliminary examination of the models and the fulfilment of the volumetric guidelines (Raumprogramm) by the competition organiser, the creation of simulations (e.g. the effect on the urban climate), the communication of the results with interactive web models and the integration of the winning project into the digital twin.

\subsection{Digital Participation in Urban Planning Procedures}

The digital twin opens up new opportunities for the city administration to win over the population for active participation in planning. One of these possibilities is the blockbuster computer game "Minecraft", where players create their own world from different "dice". The game has already been used in other cities to attract younger people in particular to participatory processes. In workshops, schools or at home, young people develop their own ideas, for example of a new neighbourhood centre, and submit them to the city as an idea. On a trial basis, the Office for Urban Development (Amt für Städtebau) has transformed parts of Zurich into a Minecraft world on the basis of the digital twin to test the applicability for future participation procedures (Fig. 13).

A web-based, interactive 3D tool was used to test another form of digital participation within the city (Fig. 14). The tool shows the complete city in the browser based on the digital twin and is based on the Java Script API from Esri. In addition to the usual navigation functions, the application 


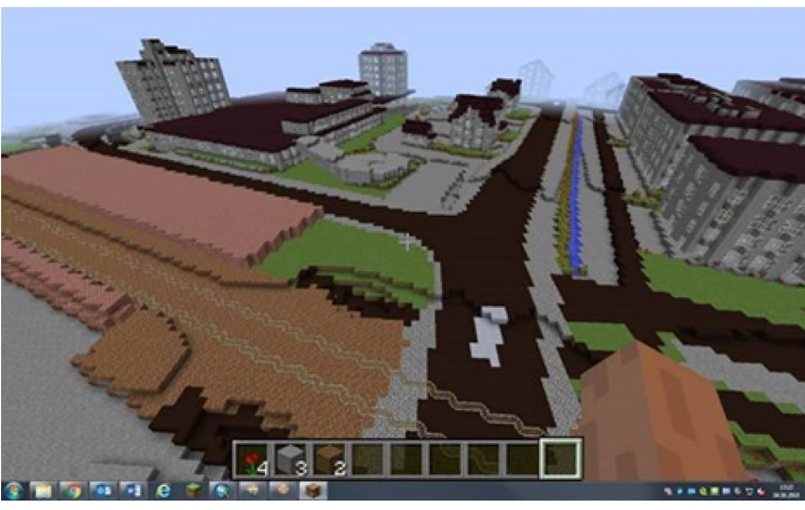

Fig. 13 Replica of the Zurich-Affoltern district in the computer game "Minecraft" (source: City of Zurich)

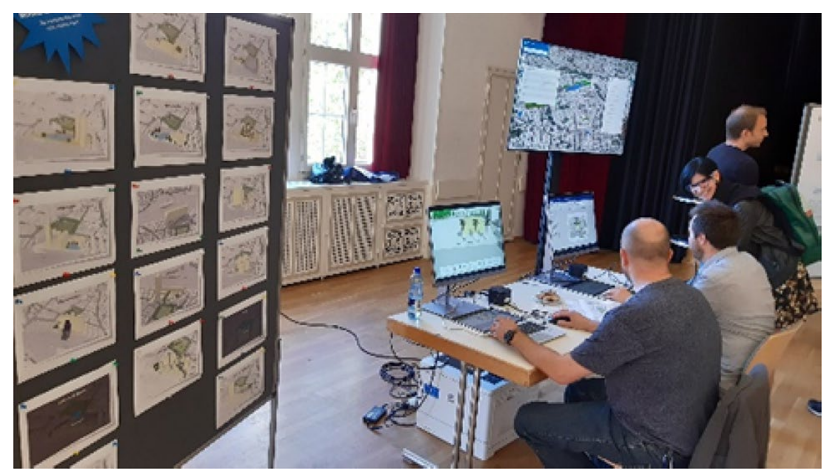

Fig. 14 Testing of the map-based participation tool by test persons (source: City of Zurich)

offers a wide range of simple design tools. Within the planning area, users can design their ideas by drawing, with just a few mouse-clicks, for instance buildings, development areas, green spaces or trees, and then submitting the finished model to the city administration.

An use case with test persons without a planning background and without special computer affinity has shown that the tool is easy and intuitive to use despite its third dimension and allows playful access to the topic of urban planning. The offer is very low-threshold, since only a computer with Internet access and browser is needed. Participation can be convenient and time independent from home. The obstacle to active participation is thus smaller than with conventional participation procedures, where a presence at an event organised by the city administration at a certain time is required. With digital applications, it could be possible to encourage more citizens to actively participate and thus further increase the acceptance of planning projects. Whether and how Minecraft or the web-based tool will be used is currently being examined by the city administration within the framework of the strategy focus "Testing Smart Participation" (SmartePartizipation 2018).

\section{Further Developments and Open Questions}

The following actions will be launched to improve the existing digital twin of the City of Zurich:

- generate more and better inter-connected 3D data

- faster updating of existing data

- systematic recording of urban furniture

- better interconnection of the BIM and GIS world

- detection and maintenance of the underground parts of the building

- building a 3D utility cadaster.

For the modelling of the subsurface, in particular the 3D Utility Cadaster, there is no specification or a common understanding from involved stakeholders what is possible today and what representation makes sense in future?

In addition, there are no corresponding jointly developed guidelines at cantonal and federal level for the modelling, recording and updating of 3D geodata.

How the worlds of BIM (Building Information Modelling) and GIS will converge? There are no practical concepts of how the two worlds will meet, where they will remain different and where they will have to interact better with each other (level of detail, automatic generalization, mutual data exchange).

The amount of data (memory) and the time required for preparation and processing in 3D increase. How to update and maintain the digital twin in the most efficient way?

The "CityGML" standard, the used data model, enables any modelling of urban objects. In our implementation, however, we do not use all the possibilities of this data model. How to use this existing data model in a sustainable and efficient way?

More and more point cloud data appear through mobile mapping. How to take advantage of this data to refine the façade of existing block models? How to integrate point cloud models of e.g. vegetation into the digital twin?

\section{Conclusion}

The digital twin is the spatial, digital model of the City of Zurich for different themes. The existing spatial data infrastructure is enriched and described with 3D spatial data and their models. The processes of construction and tracking are described holistically for the spatial data, the models and the metadata. The 3D spatial data will be the reference for further spatial data and data. They inter-connect the data and thus the digital space approaches more and more the real world. By describing the data with metadata and introducing 
lifecycle management, development and maintenance can be planned. The update can take place in real time and for certain applications the digital twin is directly connected to the real components, e.g. sensors in real space. This also changes processes in the digitalization of real space and the third dimension is consistently captured and stored. A very high importance must be attached to communication. The spatial data must be visualized attractively and performant for different interest groups. This will increase understanding and support for the digital twin. The spatial data must be Open Government Data to promote dissemination and create new applications. The access and ordering of data must be automated and the search and processing of data must be made simple and attractive.

With the further planned expansions of the 3D spatial data into an extensive digital twin and new insights from research the use of geodata will intensify and broadenfor internal and external administrative uses. The digital twin will be used to test different scenarios for future planning, for example with regard to changes in density and their effects on the urban climate or on traffic and mobility. These results will open new possibilities for discussion and decision-making within the administration and the external project participants. It also will open up new ways for the citizens to find out about projects and topics in the city and to get involved.

Open Access This article is licensed under a Creative Commons Attribution 4.0 International License, which permits use, sharing, adaptation, distribution and reproduction in any medium or format, as long as you give appropriate credit to the original author(s) and the source, provide a link to the Creative Commons licence, and indicate if changes were made. The images or other third party material in this article are included in the article's Creative Commons licence, unless indicated otherwise in a credit line to the material. If material is not included in the article's Creative Commons licence and your intended use is not permitted by statutory regulation or exceeds the permitted use, you will need to obtain permission directly from the copyright holder. To view a copy of this licence, visit http://creativecommons.org/licenses/by/4.0/.

\section{References}

Batty M (2018) Digital twins. Environ Plan B Urban Anal City Sci 45(5):817-820. https://doi.org/10.1177/2399808318796416

BauenDigital (2019) Plattform für die digitale Transformation der Schweizer Bau- und Immobilienwirtschaft. https://bauen-digit al.ch. Accessed 12 Oct 2019

Biljecki F, Stoter J, Ledoux H, Zlatanova S, Çöltekin A (2015) Applications of $3 \mathrm{D}$ city models: state of the art review. ISPRS Int J Geo-Inf 4(4):2842-2889

CH2018 (2018) CH2018 — climate scenarios for Switzerland. Technical report, National Centre for Climate Services, Zurich, p 271

Crompvoets J, Vancauwenberghe G, Ho S, Masser I, De Vries W (2018) Governance of national spatial data infrastructures in Europe. Int J Spatial Data Infrastruct Res 13:253-285. https:// doi.org/10.2902/1725-0463.2018.13.art16
CS (2017) Cooling Singapore project, Future Cities Lab, Singapore ETH-Centre. https://www.coolingsingapore.sg/the-project. Accessed 12 Oct 2019

DigitaleStadt (2019) Strategie-Schwerpunkt Digitale Stadt. Organisation und Informatik der Stadt Zürich. https://www.stadt-zueri ch.ch/fd/de/index/informatik/strategien-und-ssp/strategieschwer punkte-2018.html.Accessed 12 Oct 2019

DigitalTwinCMU (2019) Digital twin campus Muttenz-innovation platform for teaching and research. https://www.stiftungfh nw.ch/digital-twin. Accessed 12 Oct 2019

GeoCat (2019) Geometadaten. https://www.geocat.ch. Accessed 12 Oct 2019

GeoIG (2007) Bundesgesetz über Geoinformation. https://www. admin.ch/opc/de/classified-compilation/20050726/index.html. Accessed 12 Oct 2019

GeoPortal (2019) Geodaten und Anwendungen. https://www.stadt -zuerich.ch/geoportal. Accessed 13 Jan 2020

GISStrategie (2019) Strategie GIS Stadt Zürich. Geschäftsstelle, Geomatik + Vermessung Stadt Zürich. https://www.stadt-zueri ch.ch/content/dam/stzh/ted/Deutsch/geoz/Dienstleitungen /Formulare_und_Merkblaetter/Strategie_GIS_Stadt_Zueri ch_2030.pdf. Accessed 12 Oct 2019

Grieves M (2014) Digital twin: manufacturing excellence through virtual factory replication: a whitepaper, original edition. http:// innovate.fit.edu/plm/documents/doc_mgr/912/1411.0_Digit al_Twin_White_Paper_Dr_Grieves.pdf. Accessed Oct 2019 (Google Scholar)

Gruen A, Schubiger S, Qin R, Schrotter G, Xiong B, Li J, Ling X, Xiao C, Yao S, Nuesch F (2019) Semantically enriched high resolution LoD 3 building model generation. Int Arch Photogram Remote Sens Spatial Inf Sci XLII-4/W15:11-18. https:// doi.org/10.5194/isprs-archives-XLII-4-W15-11-2019

Helsinki (2019) The Kalasatama digital twins project, the final report of the KIRA-digi pilot project. https://www.hel.fi/static/ liitteet-2019/Kaupunginkanslia/Helsinki3D_Kalasatama_Digit al_Twins.pdf. Accessed 12 Oct 2019

Herthogs P, Clavier F, Knecht K, Mueller J, Drillet Z, Miao Y, Konieva K, Steentoft A, Schrotter G, Koenig R, Schlapfer M, Tunçer B, Schmitt G (2019) Big data informed urban design and governance. In: Cairns Stephen, Tunas Devisari (eds) Future cities laboratory: Indicia 02. Lars Müller Publishers, Zurich, pp 99-136

Hochhaus-Viewer (2018) Aktualisierung der Hochhausrichtlinien. Hochhaus-Viewer. https://hochhaeuser.stadt-zuerich.ch. Accessed 15 Oct 2019

München (2018) Digitaler Zwilling: Bessere Luft durch intelligente Mobilität. https://ru.muenchen.de/2018/194/Digitaler-ZwillingBessere-Luft-durch-intelligente-Mobilitaet-80933. Accessed 12 Oct 2019

Richtplan (2018) Kommunaler Richtplan Stadt Zürich. https://www. stadt-zuerich.ch/hbd/de/index/staedtebau/planung/richtplanu ng0/kommunaler-richtplan.html. Accessed 14 Oct 2019

Rotterdam (2019) Für IoT- und Smart City-Anwendungen: virtualcitySYSTEMS erstellt Digitalen Zwilling von Rotterdam. http:// www.business-geomatics.com/bgx/2019/09/09/fuer-iot-undsmart-city-anwendungen-virtualcitysystems-erstellt-digitalenzwilling-von-rotterdam/. Accessed 12 Oct 2019

SmartCity (2018) Strategie Smart City Zürich. Stadtentwickung Zürich. https://www.stadt-zuerich.ch/portal/de/index/polit ik_u_recht/stadtrat/weitere-politikfelder/smartcity/strategie/ publikationstrategie.html. Accessed 12 Oct 2019

SmartePartizipation (2018) Smarte Partizipation erproben. Stadtentwicklung Zürich. https://www.stadt-zuerich.ch/prd/de/index/ stadtentwicklung/smartepartizipation.html. Accessed 15 Oct 2019 
Stadtmodell (2019) 3D-Stadtmodell. Geomatik + Vermessung Stadt Zürich. https://www.stadt-zuerich.ch/ted/de/index/geoz/geoda ten_u_plaene/3d_stadtmodell.html. Accessed 12 Oct 2019

Strategien Zürich 2035 (2015) Zürich 2035: Strategien für unsere Stadt. Stadtentwicklung Zürich. https://www.stadt-zuerich.ch/ portal/de/index/politik_u_recht/stadtrat/strategien2035/brosc huere.html. Accessed 12 Oct 2019

van Son R, Jaw SW, Yan J, Khoo V, Loo R, Teo S, Schrotter G (2018) A framework for reliable three-dimensional underground utility mapping for urban planning. Int Arch Photogram Remote Sens Spatial Inf Sci XLII-4/W10:209-214. https://doi.org/10.5194/ isprs-archives-XLII-4-W10-209-2018

VS (2018) Virtual Singapore 2019. Government of Singapore. https ://www.nrf.gov.sg/programmes/virtual-singapore. Accessed 12 Oct 2019
Wikipedia (2019) Digital twin. https://en.wikipedia.org/wiki/Digit al_twin. Accessed Oct 2019 (Google Scholar)

Wildfire C (2018) How can we spearhead city-scale digital twins? Infrastructure intelligence. http://www.infrastructure-intelligen ce.com/article/may-2018/how-can-we-spearhead-city-scale -digital-twins. Accessed 3 Aug 2018 (Google Scholar)

Yan J, Jaw SW, Soon KH, Wieser A, Schrotter G (2019) Towards an underground utilities 3D data model for land administration. Remote Sens. 2019(11):1957

Zürich2040 (2018) Zürich 2040. Ein räumliches Konzept für die wachsende Stadt. Stadt Zürich. https://www.stadt-zuerich.ch/content/ dam/stzh/hbd/Deutsch/Staedtebau_und_Planung/Grafik\%20und \%20Foto/Planung/Richtplanung/Kommunaler\%20Richtplan/ Dokumente_KRP/Zuerich_2040.pdf. Accessed 14 Oct 2019 